\title{
Residual Risk of Transmission of HIV and Hepatitis B and $C$ by Blood Transfusion in Bukavu in the Democratic Republic of Congo
}

\author{
Jeff Maotela Kabinda ${ }^{1,2,3^{*}}$, André Nyandwe Bulabula², Philippe Donnen",5,6, Réné Fiasse7, \\ Jeff Van den Ende8, Daniel Sondag-Thull'9, Dramaix-Wilmet Michèle ${ }^{3,4,5}$ \\ ${ }^{1}$ Provincial Blood Transfusion Centre of Bukavu, Bukavu, Congo \\ ${ }^{2}$ Catholic University of Bukavu, Bukavu, Congo \\ ${ }^{3}$ Research Centre for Biostatistics, Epidemiology and Clinical Research, Brussels, Belgium \\ ${ }^{4}$ Free University of Brussels, Brussels, Belgium \\ ${ }^{5}$ School of Public Health, Brussels, Belgium \\ ${ }^{6}$ Research Centre for Health Policy and Systems/International Health, Brussels, Belgium \\ ${ }^{7}$ Catholic University of Louvain, Brussels, Belgium \\ ${ }^{8}$ Institute of Tropical Medicine, Clinical Sciences, Antwerp, Belgium \\ ${ }^{9}$ University of Liège/Belgium Red Cross, Belgium \\ Email: ${ }^{*}$ kabindaalu@yahoo.fr
}

Received 20 May 2014; revised 21 June 2014; accepted 22 July 2014

Copyright (C) 2014 by authors and Scientific Research Publishing Inc.

This work is licensed under the Creative Commons Attribution International License (CC BY).

http://creativecommons.org/licenses/by/4.0/

c) (i) Open Access

\section{Abstract}

The aim of this study was to determine the incidence rates of HIV1/2 antibodies, HBV and HCV antibodies among voluntary blood donors and to estimate the residual risk of HIV, HBV and HCV infection among blood donors in Bukavu. We conducted a follow-up cohort study of volunteer blood donors who have made at least two blood donations in Bukavu (DRC) between January 2010 and December 2012. We recorded 2986 volunteer blood donors during the study period. The residual risk of viral transmission associated with the serological window was considered as equals to the incidence rate multiplied by the duration of the serological window period divided by 365 . Seroprevalence in volunteer blood donors in Bukavu was $1.1 \%$ for HIV $1 / 2$ antibodies, $4.0 \%$ for $\mathrm{HBs} \mathrm{Ag}$ and $2.1 \%$ for hepatitis $C$ antibody. The number of conversion between two blood donations (incident cases) were observed is 8,12 and 37 donors respectively for HIV $1 / 2$, HCV and hepatitis B between 2010 and 2012. Incidence rates reported for 1000 person-years were 11.0 for HIV, 51.7 for HBV and 17.1 for HCV. The residual risk as estimated from the window was 0.6 per 1000 donations or 1/1.515 donations for HIV, 3.1 per 1000 donations or $1 / 329$ for HCV and 7.9 per 1000 donations or $1 / 126$ donations for hepatitis $B$. The residual risk is high. The screening tests are not

${ }^{*}$ Corresponding author.

How to cite this paper: Kabinda, J.M., Bulabula, A.N., Donnen, P., Fiasse, R., Van den Ende, J., Sondag-Thull, D. and Michèle, D.-W. (2014) Residual Risk of Transmission of HIV and Hepatitis B and C by Blood Transfusion in Bukavu in the Democratic Republic of Congo. Open Journal of Epidemiology, 4, 157-163. http://dx.doi.org/10.4236/ojepi.2014.43021 
enough to ensure safe blood. The reduction of residual risk would be achieved through the effectiveness of preventive measures taken for transfusion chain, before and after the biological qualification of blood donation.

\title{
Keywords
}

\author{
Residual Risk, Hepatitis, HIV, Blood Donation
}

\section{Introduction}

In sub-Saharan Africa, given the large number of HIV and hepatitis B and C infected subjects, one in 20 adults is living with HIV [1], an adult in 13 is living with hepatitis B and one in 10 adults with hepatitis C [2]-[8]. Hepatitis viruses are responsible for hepatitis acute, chronic and hepatocellular carcinomas while HIV causes millions of deaths from a variety of opportunistic diseases (tuberculosis, Kaposi, diarrhea various germs and other infections). All its manifestations affect the age of people who are active in all areas of life group. This then threatens development of countries [1] [8]. The risk of transmission of these three virus from infected blood collected from donors during window period is not negligible. It is important to take appropriate precautions to reduce it. Several measures, including the qualification and selection of blood donors have been developed to ensure blood safety. Despite an evolution and improvement of all these measures, the residual risk is still too high. This is a risk of transmission of viruses whose markers (antibodies) are detected during the period preceding their appearance to be detected in the laboratory [9]-[12]. The strategy of the qualification and selection of blood donors has shown good results with the reduction of the residual risk of viral markers in industrialized countries [11] [13]. The estimation of residual viral risk in blood products is an indicator to evaluate the quality and the management of the provision process of these products [14]. A direct estimation of the transfusion risk would be recipient's follow-up to study the seroconversion; and indirect estimation is proposed by Schreiber [15] method, based on the incidence of each viral infection in the population of blood donors and the duration of the window period. These residual risk assessments have shown that in industrialized countries the risk is mastered in France without genomic screening, the risk was estimated to 1/1,400,000 donations for HIV 1/1,000,000 for HCV and $1 / 400,000$ for HBV [11] while in Africa it is high in the order of 1/5780 donations for HIV, 1/406 donations for HCV and 1/383 donations for HBV in Ivory Coast [16] and 1/28,571 donations for HIV and 1/976 donations for the HBV Senegal [9]. This study aims to determine the incidence rate of HIV, HBV and HCV and to estimate the residual risk of HIV, HBV and HCV among voluntary blood donors in Bukavu RDC.

\section{Methodology}

This is a follow-up study of a cohort of volunteer blood donors. It focused on blood donors who attended the hospital blood banks of the General Provincial Referral Hospital in Bukavu, General Referral Hospital of Panzi and Provincial Blood Transfusion Center (CPTS) between $1^{\text {st }}$ January 2010 and December $31^{\text {st }}, 2012$. The provincial hospital and the hospital of Panzi are academic hospitals that are in the health district of Bukavu, the capital of the province of South Kivu. The study focused on regular volunteer blood donors meaning donors who donated blood at least twice during the study period and whose first blood donation was negative. Time between the two donations should not have exceeded one year. The donors who made only one donation during the period of our study were not considered for the analysis of residual risk.

\subsection{Data Collection}

A pre-donation interview using a questionnaire was carried out before each donation to detect contra-indications to donate blood. This interview was conducted either by a doctor or by a nurse responsible for transfusion in the institution, trained for this purpose. Information to know the date of donation, sex, age, occupation, class of donors (new or old, volunteer or family) were collected from the blood donors. All this information was recorded on a single paper sheet and a code was assigned to each blood donor. The code was used for the laboratory tests The anonymity of the donor was respected. All laboratory results were kept confidential. 


\subsection{Serology}

For each blood donor, after filling the pre-donation standard questionnaire, a blood sample was collected in a coded tube without anticoagulant and kept at room temperature. After complete coagulation, it was centrifuged to settle the serum. The rapid test Determine ${ }^{\mathrm{R}}$ HIV for screening anti-HIV1/2 antibodies, Determine ${ }^{\mathrm{R}}$ HBV for detecting the surface antigen of hepatitis B (AgHbs) virus and Determine ${ }^{\mathrm{R}} \mathrm{HCV}$ for the detection of hepatitis C virus antibodies were made. All the sera have been tested by a second analysis in a ELISA test.

The following reagents were used for HIV: Vironostika ${ }^{\mathrm{R}}$ VIH Uni-FormII Ag/Ab 4th generation laboratory Biomérieux; for HBV: Hepanostika ${ }^{\mathrm{R}}$ AgHbs System Microelisa Laboratory Biomérieux; for HCV: Monolisa ${ }^{\mathrm{R}}$ Anti-VHC Ab de BIO-RAD.

\subsection{Statistical Analysis}

After data collection, entry thereof was performed using the Epi Info software, Version 3.5.1. Analyses were performed by STATA Version 12 and OpenEpi. For sociodemographic variables of blood donors descriptive analysis consisted of obtaining proportions for variables into categories and median accompanied by the minimum and maximum for age. Chi square test of Pearson was used to compare proportions of socio-demographic variables; the significance level used was 0.05 .

Seroprevalence of virus markers was calculated on entire population of donor during the period (new and former donors with positive serology). Was considered positive donations that was one of the two tests used (rapid test and ELISA).

The incidence rate was calculated by dividing the number of incident cases by the number of person-years. The number of incident cases for each marker corresponds to the number of donors with a negative result followed by a positive donation confirmed for the marker, 95\% Confidence interval of was calculated.

The number of person-years is the amount of time tracking of each donor cohort, between the first and last donation, between the first donation and any positive donation. The time has been expressed in years and the incidence rate was obtained for 1000 person-years.

The residual risk per 1000 donations was calculated by multiplying the incidence by the duration of the window in days rate divided by 365.

The window period (in days) or serological window is the period between infection with the virus and the onset of plasma antibodies produced by the body. Serological windows were obtained from literature data: 22 days for HIV, 56 days for HBV and 66 for HCV [9] [11].

\section{Results}

During the study period, we recorded 5071 voluntary donations among which 1182 (39.5 \%) were from new blood donors and 1804 came from regular donors with an average of three donations. Our blood donors were male in $73.2 \%$ of cases, single in $71 \%$ of cases in total. Concerning the profession $41.7 \%$ of blood donors were pupils or students and $28.4 \%$ without occupation. The median age of blood donors stood at 23 years with a minimum of 18 and a maximum of 65 years. A majority of blood donors were in the age group under 30 years (74\%).

The number of blood donors has remained stable between 2010 and 2011 but decreased in 2012 mainly in new donors. The number of blood donations has increased since 2010. The overall prevalence in those three years was $4 \%$ (187 positive/4726 donations) to the surface antigen of hepatitis B, 2.1\% (105 positive/5016 donations) for antibodies against hepatitis C and 1.1\% (57 positive/5068 donations) for anti HIV (Table 1). During the study period we observed discordances between negative donations by rapid tests but positives by Elisa tests: three donations for HIV or 6 per 10,000 donations, 1 case for HBV or 2 per 10,000 donations and 2 cases for HCV or 4 per 10,000 donations. One blood donation was HIV positive with rapid test but negative to Elisa, two blood donations had a HBV positive result in the rapid test but a donation was negative and the other was indeterminate to ELISA and one donation of blood was hepatitis C positive with in fast test but negative in ELISA test. A statistically significant difference in the prevalence of $\mathrm{HBV}$ was observed between new donors and regular donors $(5.0 \%$ vs $3.3 \%, \mathrm{p}=0.003)$, between men and women $(4.4 \%$ vs $2.8 \%, \mathrm{p}=0.01)$ and between age groups (4.4\% for those under 30 years, $3.4 \%$ for donors between 31 and 40 years and $2.4 \%$ for those aged 41 years and older, $\mathrm{p}=0.04$ ). The prevalence of antibodies against hepatitis $\mathrm{C}$ was significantly different by cate- 
Table 1. Seroprevalence of HIV, HBsAg and HCV in blood donors in Bukavu.

\begin{tabular}{ccccc}
\hline Year & 2010 & 2011 & 2012 & Total \\
\hline Number of volunteer blood donors & 1079 & 1014 & 893 & 2986 \\
New donors & 491 & 384 & 307 & 1182 \\
Regular donors & 588 & 630 & 586 & 1804 \\
Number of blood donations & 1570 & 1715 & 1786 & 5071 \\
Hepatitis B Prevalence (\%) & 4.2 & 5.2 & 3.7 & 4.0 \\
Hepatitis C Prevalence (\%) & 3.8 & 2.8 & 1.5 & 2.1 \\
HIV Prevalence (\%) & 0.8 & 1.2 & 1.3 & 1.1 \\
\hline
\end{tabular}

gory of blood donors (new $2.8 \%$ against $1.6 \%$ in regular; $\mathrm{p}=0.004$ ). We did not observe any significant difference in HIV prevalence according to different socio-demographic characteristics of blood donors. In addition, we observed 6 donations in 4697 or $0.1 \%$ coinfection with hepatitis B and hepatitis C, 4 donations in 4723 or $0.1 \%$ coinfection with HIV and hepatitis B, 2 in 5015 gifts or $0.04 \%$ with an HIV and hepatitis C coinfection and 12 donations in $4696(0.2 \%)$ with the three viruses.

The seroconversion between 2010 and 2012 were 37 cases for HBV, 12 for hepatitis C and HIV 8. Incidence rates reported in 1000 person-years were, respectively, for HBV, HCV and HIV 51.7, 17.1 and 11.0. The residual risk of transmission of infectious agents by blood transfusion of labile blood products found during the three years of follow-up cohort of blood donors was: one for 1515 blood donations for HIV, one for 126 donations for HBV and one for 329 for hepatitis C (Table 2).

\section{Discussion}

Our study on the estimation of the risk of transmission of HIV, HBV and HCV by blood transfusion has focused on voluntary donors who donated blood at least twice during the period between 2010 and 2012. It does not take into account donations from occasional donors (family or paid) or from new donors. Given the high proportion of these three viruses in the category of occasional donors and new donors [2] [6], the risk of transmission by blood units from this group of donors should be more important. Incident cases positive results in screening tests for three viruses have not been confirmed, it may cause misclassification and an overestimation of the residual risk. The calculation of residual risk based on duration of serological window was fixed with a genomic screening [10], whereas we used the ELISA tests. Despite these limitations, the residual infectious risk is representative of our endemic context and reliable given the respect of the duration of the 3-year study and consideration of seroconversion.

The number of blood donations was 5071 for three years with an average of 1600 per year for donations Bukavu which is inhabited by nearly one million people. We are very far to meeting the standards of the World Health Organization that wants the number of donors is $1 \%$ to $2 \%$ of the population of a country. This observation is the same for the rest of the country. The DRC has a national blood transfusion center in the capital, with 11 provincial centers, one in each province is still far to collect donations of blood meets the needs as is the case in other African countries Saharan [9] [17] [18]. In 2011 for a population of nearly 70 millions, 372,258 blood bags were collected.

The blood donors are young, pupils or students. Africa's population is young and this characteristic is found in most studies on African blood donors [2]-[6]. Our blood mobile collections take place often in universities and schools in collaboration with non-profit civil society gathered in platform friendly volunteer blood donors associations.

HIV prevalence in our study is $1 \%$; it is comparable to that found in the same city by Namululi [19] between 2001 and 2005. This shows the stability of this viral infection in this population group. This prevalence is higher than that observed in Dakar (0.8\%) in 2009, but lower than that found among voluntary blood donors in Burkina Faso $2.3 \%$ [20]. The reason is that Senegal is a country with very low HIV prevalence unlike in Burkina Faso. The seroprevalence of HBV in our study (4\%) is similar to that found by Namululi (3.7\%) [19]. Indeed the proportion of HBV (4\% between 2010 and 2012 in our study and 3.7\% between 2001 and 2005 in the study of Na- 
Table 2. Incidence rate of HIV, HBV and HCV and residual risk estimate from 2010 to 2012 in Bukavu.

\begin{tabular}{|c|c|c|c|c|c|}
\hline & \multirow{2}{*}{ Person-years } & \multirow{2}{*}{ Incident cases } & Incidence rate per 1000 person-years & Serological window & \multirow{2}{*}{$\begin{array}{l}\text { Residual Risk per } \\
1000 \text { donations }\end{array}$} \\
\hline & & & $(95 \% \mathrm{CI})$ & ( day) & \\
\hline HBV & 715 & 37 & $51.7(36.9-70.6)$ & 56 & $7.93(1 / 126)$ \\
\hline HCV & 704 & 12 & $17.1(9.2-28.9)$ & 66 & $3.09(1 / 329)$ \\
\hline HIV & 727 & 8 & $11.0(5.1-20.9)$ & 22 & $0.66(1 / 1515)$ \\
\hline
\end{tabular}

mululi) shows stability of chronically in our population, although we observed a decrease in 2012 (Table 1). Prevalence of hepatitis B mainly affects new blood donors, men donor and less than 30 years. The explanation is that in this group of the population (blood donors and men less than 30 years), certain practices such as scarification and tattooing for various reasons may be the cause of the infections [21]. The organization of awarenessraising about the modes of transmission of this virus could probably play a role in reducing the incidence rate [9].

All blood donations with a positive infectious marker were discarded. Transmissions to recipients have been reduced by strategies put in place for the safety of blood products such as biological systematic qualification of any unit of blood. Despite these different mechanisms of blood safety (quality assurance, selection of blood donors), the risk of transmission of HIV and hepatitis B and C still exists [9] [22]. This risk can be attributed to factors such as handling errors, a variant not recognized by certain reagents such as HIV-1 group O and HIVnegative infectious donation in a chronic carrier or in a recently infected individual (window period) [9] [10] [14]. The risk due to the error handling is very low. With a high estimate of $0.25 \%$ errors and given the prevalence of the marker in blood donations, the probability of an error has been estimated in France, for a million donations, 0.009 for HIV, HCV and HBV 0.13 to 0.11 [13]. Unrecognized variants by some test kits are extremely rare. The highest risk is due to donors who have been collected early after infection, before the advent of serological markers. This last factor of residual risk has been the subject of our study. We found an incidence rate per 1000 person-years of 51.7, 17.1 and 11.0 respectively for HBV, Hepatitis C and HIV. These rates expose the risk of transmission of these three viruses by transfusion because the probability that a receiver becomes infected after exposure to the virus is 100\% [23]. The residual risk of HIV found in our study 1/1515 donations is very high compared to that observed in the South Africa [24] between 1/10,909 donations and 1/25,641 donations, Côte d'Ivoire 1/5780 donations [16] and Senegal 1/28571 donations [9] but it is lower than that found in Ghana (1/290 donations ) [5]. The difference is explained by the fact that the prevalence of HIV among blood donors in Bukavu is higher than that of HIV among blood donors in South Africa 0.8\% [25] and Senegal (0.8\%). But the residual risk in our study is lower than that observed in Ivory Coast because HIV prevalence in the general population is high as $10 \%$. One explanation may be that the study of Ivory Coast has received confirmation tests for all the positive cases, whereas in our study the rapid Elisa tests were used. The residual risk of transmission of hepatitis B and C found here is similar to that found in other studies 1/121 donations in Guinea for HBV and 1/406 donations in Ivory Coast to the risk of hepatitis C [16] [23].

In our study, the residual risk is different for the three markers. The risk of residual HBV is 12 times higher than that of HIV, and 3 times that of HCV while the residual risk of HCV is 5 times higher than HIV. This can be explained in part by the length of the window relative to that of HIV and the other by the higher rate of incidence of HBV compared to HIV and HCV rate associated with a higher prevalence in the general population associated with greater efficiency of sexual transmission of HCV and HBV as HIV [23].

\section{Conclusion}

The residual risk of HIV, hepatitis B and C in our study is very high and joined the trends of African Studies. Despite the limitations of the study, the numbers found are in line with the epidemiological context of the country. Among blood donors, it is imperative to increase sensitization in order to change behavior and cause them to be loyal donors to reduce the risk of these viruses. The improvement over the last two decades of serological screening tests and even the introduction of genomic screening allows hope for reducing this risk of infection. However, the level of blood safety depends also and above all the effectiveness of prevention measures taken at each stage of the transfusion chain. These strategies can be temporary or definitive, taken upstream and/or 
downstream of the biological qualification of blood donations. These measures are: the limitation of transfusion indications at provider level, the selection of donors with information and medical interviews pre-donation screening for viral markers by serological tests. It will make available these tests in all structures even in the most remote areas, before thinking to develop genomic screening and inactivation of labile blood products in our context.

\section{Acknowledgements}

To all the brave people who save lives by donating blood.

\section{References}

[1] UNAIDS (2012) World AIDS Day Report, Genève

[2] Kra, O., N’Dri, N., Ehui, E. and Ouattara, B. (2007) Prevalence of HBs Antigen in Blood Donors in the Bouaké Regional Centre of Blood Transfusion in 2001. Bulletin de Société Pathologie Exotique, 100, 127-129.

[3] Batina, A., Kabemba, S. and Malengela, R. (2007) Infectious Markers among Blood Donors in the Democratic Republic of Congo (DRC). Revue Medicale de Bruxelles, 28,145-149.

[4] Moore A, Herrera, G., Nyamongo, J., Lackritz, E., Granade, T., Nahlen, B., et al. (2001) Estimated Risk of HIV Transmission by Blood Transfusion in Kenya. Lancet, 358, 657-660. http://dx.doi.org/10.1016/S0140-6736(01)05783-X

[5] Candotti, D., Sarkoclie, F. and Allain, J. (2001) Residual Risk of Transfusion in Ghana. British Journal of Haematology, 113, 37-39. http://dx.doi.org/10.1046/j.1365-2141.2001.02679.x

[6] Dagnra, A.Y., Prince-David, M., Agbénu, S., Ouro-Akpo, T. and Hounkpati, F. (2002) Prevalence and Risk of HCV Transmission after Detection of HIV and HBV in Blood Donors. Médecine et Maladies Infectieuses, 32, 315-319.

[7] Allain, J.P., Candotti, D., Soldan, K., Sarkodie, F., Phelps, B., Giachetti, C., et al. (2003) The Risk of Hepatitis B Virus Infection by Transfusion in Kumasi, Ghana. Blood, 101, 2419-2425. http://dx.doi.org/10.1182/blood-2002-04-1084

[8] Allain, J.P., Owusu-Ofori, S. and Bates, I. (2004) Blood Transfusion in Sub-Saharan Africa. Transfusion Alternatives in Transfusion Medicine, 1, 16-23. http://dx.doi.org/10.1111/j.1778-428X.2004.tb00108.x

[9] Touré-Fall, A.O., Dièye, T.N.D., Sall, A., Diop, M., Seck, M., Diop, S., Thiam, D. and Diakhaté, L. (2009) Residual Risk of Transmission of HIV and HCV, in Senegalese National Blood Bank from 2003 to 2005. Transfusion Clinique et Biologique, 16, 439-443. http://dx.doi.org/10.1016/j.tracli.2009.09.005

[10] Pillonel, J., Brouard, C., Laperche, S., Barin, F., Bernillon, P. and de Valk, H. (2009) Quantitative Estimate of the Risk of Blood Donation Contamination by Infectious Agents. Transfusion Clinique et Biologique, 16, 138-145. http://dx.doi.org/10.1016/j.tracli.2009.03.016

[11] Pillonel, J. and Laperche, S. (2004) Trends in Residual Risk of Transfusion-Transmitted Viral Infections (HIV, HCV, HBV) in France between 1992 and 2002 and Impact of Nucleic Acid Testing. Transfusion Clinique et Biologique, 11, 81-86. http://dx.doi.org/10.1016/j.tracli.2004.02.004

[12] Lawson-Ayayi, S. and Salmi, L.R. (1997) Transfusion Transmitted Infections and Efficacy of Predonation Blood Donor Selection. Transfusion Clinique et Biologique, 6, 513-521. http://dx.doi.org/10.1016/S1246-7820(97)80076-6

[13] Barlet, V. (2001) Technological Evolutions in Blood Donation Screening and Their Impact on the Residual Risk. Transfusion Clinique et Biologique, 18, 292-301. http://dx.doi.org/10.1016/j.tracli.2011.02.025

[14] Courouce, A.M. and Pillonel, J. (1996) Risk of Transfusion-Transmitted Viral Infections. Transfusion Clinique et Biologique, 3, 13-18. http://dx.doi.org/10.1016/S1246-7820(96)80008-5

[15] Schreiber, G.B., Busch, M.P., Kleinman, S.H. and Korelitz, J.J. (1996) The Risk of Transfusion-Transmitted Viral Infections. New England Journal Medecine, 334, 1685-1690. http://dx.doi.org/10.1056/NEJM199606273342601

[16] Ouattara, H., Siransy-Bogui, L., Fretzd, C., Diane, K.M., Konate, S., Koidio, A., Minga, K.A., Hyda, J., Koffi-Abe, N., Offoumou, A.M. and Abissey, S. (2006) Residual Risk of HIV, HVB and HCV Transmission by Blood Transfusion between 2002 and 2004 at the Abidjan National Blood Transfusion Center. Transfusion Clinique et Biologique, 13, 242-245. http://dx.doi.org/10.1016/j.tracli.2006.03.015

[17] CDC (2009) Progress toward Strengthening Blood Transfusion Services 14 Countries, 2003-2007. JAMA, 301, 153154. http://dx.doi.org/10.1001/jama.301.2.153

[18] Ségbéna, A.Y., Fétéké, L., Bikandou, B., Awitala, E.J. and Koura, A.G. (2009) Situation and Perspectives of Blood Transfusion in Togo. Transfusion Clinique et Biologique, 16, 460-463. http://dx.doi.org/10.1016/j.tracli.2009.07.002

[19] Namululi, A.B., Guerrieri, C. and Dramaix, W.M. (2013) Prevalence and Incidence of HIV and Hepatitis B among 
Blood Donors and Estimated Residual Risk of Transmission of HIV and HBV Virus by Blood Transfusion. A Study at the Provincial General Referee Hospital Bukavu, Democratic Republic of the Congo. Revue d'Épidémiologie et de Santé Publique, 61,139-144. http://dx.doi.org/10.1016/j.respe.2012.09.005

[20] Nébié, K.Y., Olinger, C.M., Kafando, E., Dahourou, H., Diallo, S., et al. (2007) Lack of Knowledge of Blood Donors in Burkina Faso (West Africa); Potential Obstacle to Transfusion Security. Transfusion Clinique et Biologique, 14, 446-452. http://dx.doi.org/10.1016/j.tracli.2007.12.005

[21] Kabinda, J.M. and Katchunga, B.P. (2010) Viral Hepatitis B and C in Individuals Infected with Human Immunodeficiency Virus in Bukavu (South-Kivu), Democratic Republic of Congo. Journal Africain d'Hépato-Gastroentérologie, 4, 230-235. http://dx.doi.org/10.1007/s12157-010-0204-8

[22] Le Cosquer, P. (2000) Survey on the Anaesthesists and ICU Doctors Normal Practice on Blood Transfusions and Haemovigilance. Annales Françaises d'Anesthésie et de Réanimation, 19, 485-491. http://dx.doi.org/10.1016/S0750-7658(00)00227-6

[23] Loua, A., Sow, E.M.L., Magassouba, F.B., Camara, M. and Baldé, M.A. (2004) Evaluation of Residual Infectious Risk among Blood Donors in National Center of Blood Transfusion in Conakry. Transfusion Clinique et Biologique, 11, 98-100. http://dx.doi.org/10.1016/j.tracli.2004.01.004

[24] Sitas, F., Fleming, A.F. and Morris, J. (1994) Residual Risk of Transmission of HIV through Blood Transfusion in South Africa. South African Medical Journal, 84, 142-144.

[25] du P. Heyns, A., Benjamin, R.J., Ronel Swanevelder, J.P., Laycock, M.E., Pappalardo, B.L., Crookes, R.L., Wright, D.J. and Busch, M.P. (2006) Prevalence of HIV-1 in Blood Donations Following Implementation of a Structured Blood Safety Policy in South Africa. JAMA, 295, 519-526. http://dx.doi.org/10.1001/jama.295.5.519 
Scientific Research Publishing (SCIRP) is one of the largest Open Access journal publishers. It is currently publishing more than 200 open access, online, peer-reviewed journals covering a wide range of academic disciplines. SCIRP serves the worldwide academic communities and contributes to the progress and application of science with its publication.

Other selected journals from SCIRP are listed as below. Submit your manuscript to us via either submit@scirp.org or Online Submission Portal.
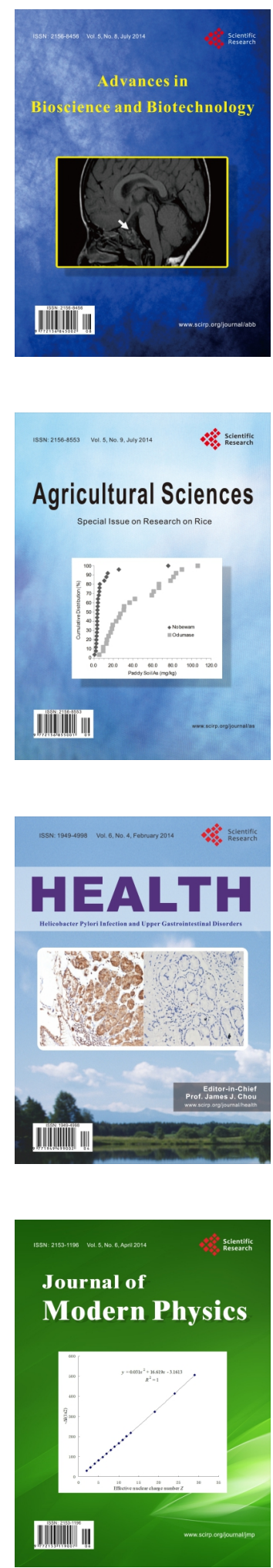
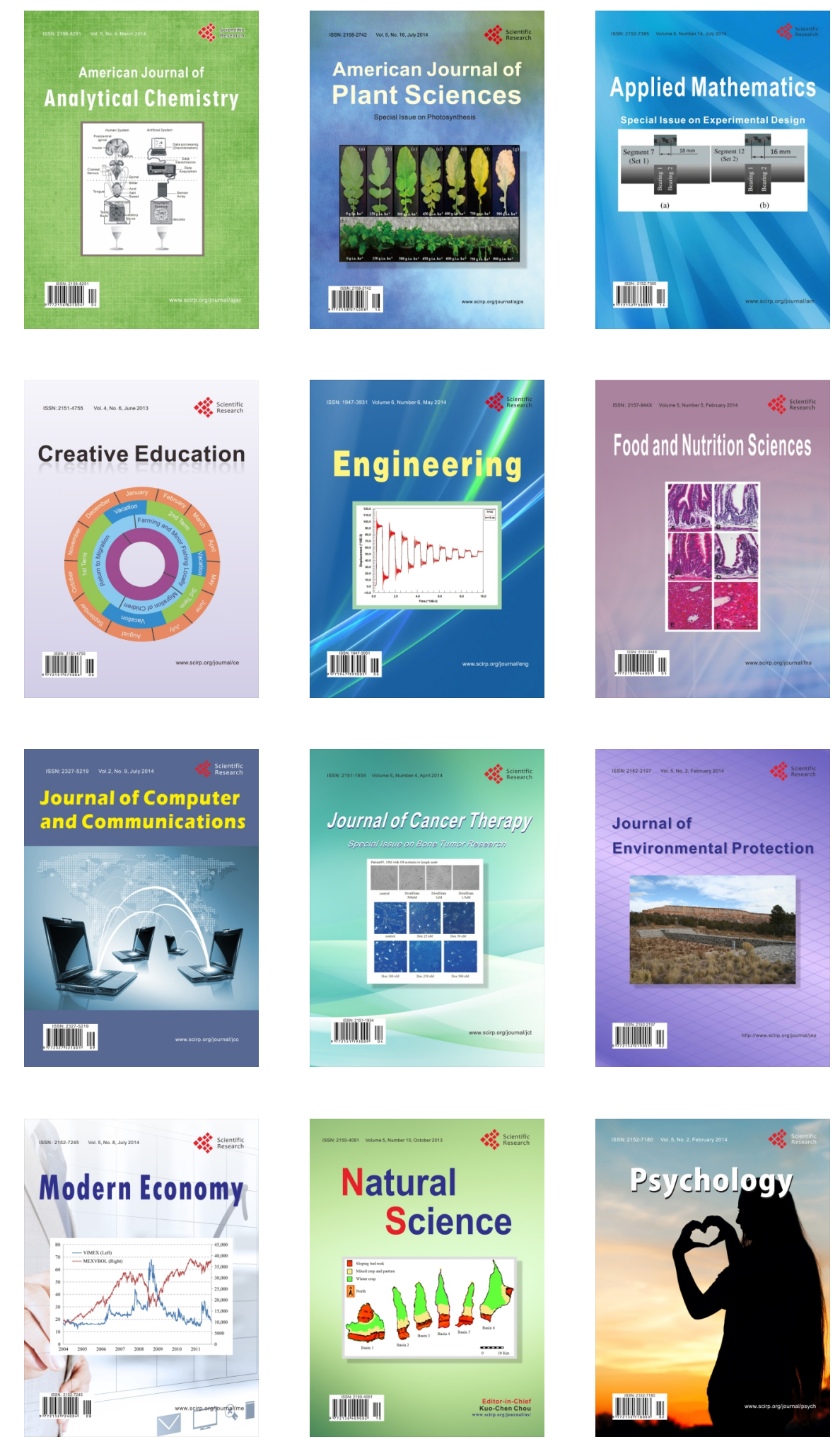